\title{
Tinjauan Ulang Sistem Pemindaian Termal Tubuh Manusia dengan Sensor Suhu Pyroelectric
}

\author{
Anwar Mujadin $^{1 *}$, Yaya Suryana ${ }^{1,2}$ \\ ${ }^{1}$ Program Studi Teknik Elektro, Fakultas Sains dan Teknologi, \\ Universitas Al Azhar Indonesia, Jl. Sisingamangaraja, Jakarta 12110 \\ ${ }^{2}$ Badan Pengkajian dan Penerapan Teknologi, Jl. MH.Thamrin 8, Jakarta 10340 \\ *Penulis untuk Korespondensi: amujadin@uai.ac.id
}

\begin{abstract}
Abstrak - Elemen sensor pyroelectric sangat sensitif terhadap jangkauan lebar radiasi dan sudut jatuh incoming radiasi panas badan manusia pada panjang gelombang 5-15 $\mu \mathrm{m}$ [1]. Signal respon sensor pyroelectric dapat didekatkan oleh dua buah grafik exponensial sebagai akibat perubahan kapasitansi dalam amplifier. Waktu naik dan turun dari signal tegangan dapat ditentukan oleh $\tau_{e}$ (tetapan waktu elektrik) dan $\tau_{t}$ (tetapan waktu termal) yang sebelumnya telah melewati bandpass filter. Dalam tulisan ini, akan dijelaskan secara rinci semua aspek yang menyangkut sistem pemindaian termal tubuh manusia dengan sensor suhu pyroelectric.
\end{abstract}

Abstract - Pyroelectric sensor element is very sensitive to a wide range of incoming radiation and heat radiation angles of the human body at 5-15 $\mu \mathrm{m}$ wavelength [1]. The response signal of the pyroelectric shown by two exponential graph as a result of changes capacitance in the amplifier. Rise and fall time of the voltage signal can be determined by the $\tau_{e}$ (electric time constant) and $\tau_{t}$ (thermal time constant) through a bandpass filter. In this paper, will be explained in detail how Infrared motion detector components work.

Keywords - Pyroelectric, Pyroelectric electronics design

\section{PENDAHULUAN}

$\mathrm{I}$ nfra dalam bahasa latin berarti "di bawah", dengan demikian "infra merah" menunjuk ke daerah berada di bawah spektrum cahaya (warna) tampak. Daerah inframerah ditempatkan di antara cahaya tampak dan gelombang mikro dari spektrum elektromagnetik. Bila sebuah objek dipanasi maka akan menyebarkan energi pada gelombang cahaya infra merah (hot spectrum area). Semua objek pada suhu kamar menyebarkan energi pada spektrum cahaya infra merah, Lebih tinggi suhu dari satu objek, maka lebih tinggi pula energi radiasi spektral (emittance). Pada suhu kamar terjadi emittance puncak pada panjang gelombang $10 \mu \mathrm{m}$. Matahari mempunyai suhu sebesar $5.900 \mathrm{~K}$ dengan puncak emittance pada panjang gelombang $0,53 \mu \mathrm{m}$ memancarkan energy ultra violet berada jauh di luar daerah infra merah [2]. Pada gambar 1 diperlihatkan energi radiasi spektral versus panjang gelombang [2].

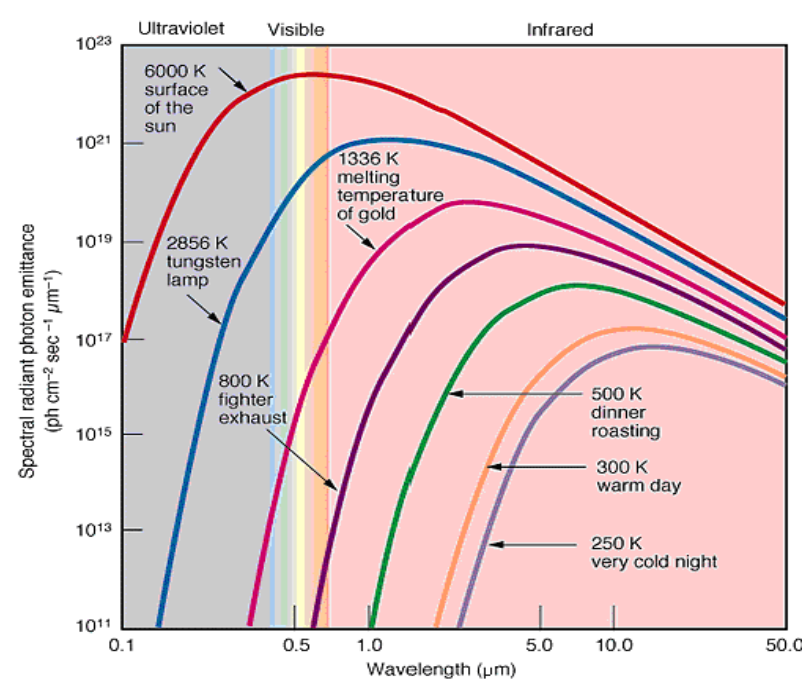

Gambar 1. Energi radiasi spektral versus panjang gelombang [2] 


\section{TINJAUAN PUSTAKA}

Sensor pyroelectric dibuat dari suatu bahan crystalline yang menghasilkan muatan elektrik permukaan ketika disinari radiasi infra merah (panas). Dalam sensor ini terpasang satu, dua atau empat element crystalline. Dalam penelitian ini digunakan pyroelektric yang mempunyai dua elemen sensor (dual crystalline). Elemen sensor sangat sensitif terhadap jangkauan lebar radiasi sehingga diperlukan sebuah filter jendela untuk membatasi incoming radiasi. Dengan kemasan Transistor Outline 5 (TO5), filter tersebut dapat mendeteksi radiasi dengan panjang gelombang 5-15 $\mu \mathrm{m}$ yang sensitif terhadap radiasi panas badan manusia. Bentuk sensor pyroelectric dan simbol diperlihatkan pada gambar 2 di bawah ini [3].
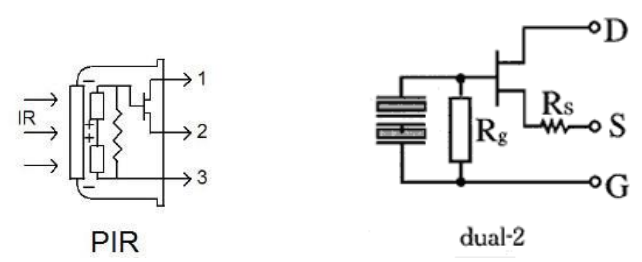

Gambar 2. Bentuk dan simbol pyroelectric sensor [3].

Power dihubungkan ke drain (pin 1) dan ground (pin3) sedangkan sinyal keluaran melewati resistor shunt RS (pin 2) untuk dihubungkan ke external amplifier.

Pada gambar 3 diperlihatkan berbagai macam jenis pyroelektric dengan filter jendela yang bervariasi dalam kemasan TO5 [3].

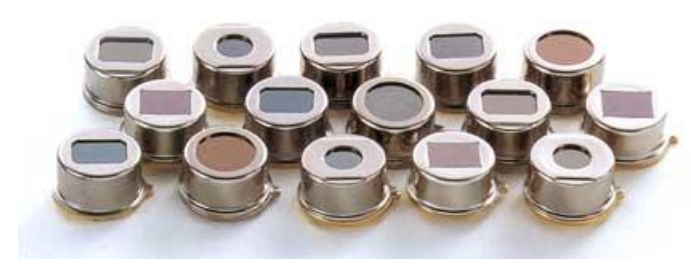

Gambar 3. Pyroelectric sensor dalam berbagai jenis jendela filter kemasan TO5 [3].

Bila ip direpresentasikan sebagai arus yang melewati sensor akibat fluktuasi radiasi suhu menyebabkan perubahan suhu $\Delta T p$ maka:

$$
i p=p A_{s} \frac{d T_{p}}{d t}
$$

Dimana $p$ adalah pyroelectric kontanta bahan, dan $A_{s}$ adalah area elemen dari sensor [3].

Pada tabel 1 diperlihatkan parameter PIR350 phyroelectric sensor [4].

Tabel 1. Parameter PIR325 pyroelectric sensor [4].

\begin{tabular}{lc}
\hline \multicolumn{1}{c}{ Parameter } & Value \\
\hline Sensitive area $(\mathrm{mm})$ & $2 \times 1$ \\
Responsivity $(\mathrm{V} / \mathrm{W})$ & 3.300 \\
Spectral response $(\mu \mathrm{m})$ & $5-14$ \\
Noise equivalent power $(\mathrm{nW})$ & 0,96 \\
Detectivity $(\mathrm{cm} \sqrt{ } \mathrm{Hz} / \mathrm{W})$ & $1,5 \times 10^{8}$ \\
Signal output $(\mathrm{mVp}-\mathrm{p})$ & 3900 \\
Response time $(\mathrm{ms})$ & 500 \\
\hline
\end{tabular}

Signal respon dapat di dekatkan oleh dua buah grafik exponensial sebagai akibat perubahan kapasitansi dalam amplifier. Waktu naik turun dari signal tegangan dapat didekatkan oleh persamaan dibawah ini [4].

$$
S=S_{0}\left[1-\exp \left(-\frac{t}{\tau_{e}}\right)\right] \exp \left(-\frac{t}{\tau_{t}}\right)
$$

dimana $S_{0}$ representasi dari respon steady state. Kita dapat melihat bahwa tanggapan ditentukan oleh $\tau_{e}$ (tetapan waktu elektrik) dan $\tau_{t}$ (tetapan waktu termal), respon frekuensi ini telah melalui bandpass filter. Upper cut off frekuensi berhubungan dengan $\tau_{e}$ (tetapan waktu elektrik), sedangkan lower cutoff frekuensi berhubungan dengan $\tau_{t}$ (tetapan waktu termal) [4]. Bentuk grafik respon diperlihatkan pada gambar 4 berikut:
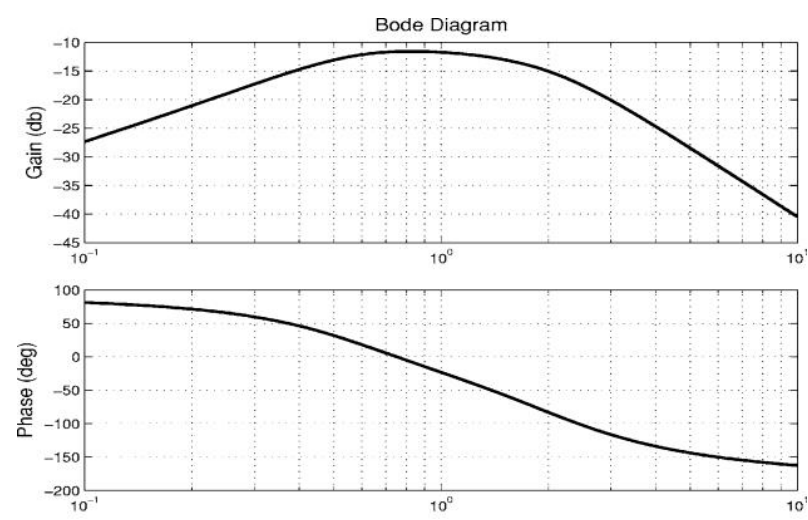

Gambar 4. Frekuensi respon dari phyroelectric sensor pada lower dan upper cutoff [4]. 
Lensa Fresnel FL65 adalah sebuah lensa plano convex (plat) ibuat dari suatu bahan yang dapat memfokuskan radiasi infra merah suhu badan manusia dengan panjang gelombang dari 8 sampai $14 \mu \mathrm{m}$. dengan lensa ini pyroelectric sensor dapat mendeteksi perubahan gelombang infra merah pada sudut $120^{\circ}$ [4]. Pada gambar 5 (a, b dan c) diperlihatkan lensa Fresnel dan penempatannya dengan sensor pyroelectric.

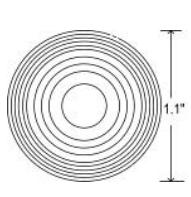

(a)

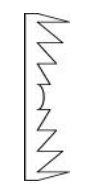

(b)

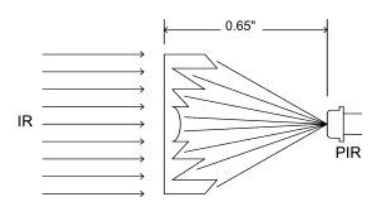

(c)
Gambar 5. (a) lensa Fresnel tampak samping, (b) lensa Fresnel tampak depan(c) penempatan lensa Fresnel dengan sensor [4].

\section{METODE PENELITIAN}

Langkah dan strategi dalam penyelesaian penelitian pembuatan prototipe sistem cerdas pengintai ruangan berbasis komunikasi nirkabel terdiri dari:
a. Penentuan spesifikasi komponen
b. Pemilihan komponen
c. Perancangan
d. Pembuatan prototip
e. Pengujian prototip

Dalam tulisan ini akan dibahas mengenai rancang bangun driver penguat pyroelectric sensor PIR350 terutama dalam menentukan penguatan termasuk penentuan sinyal Band Pass Filter (BPF) yang dirancang hanya untuk mendeteksi pergerakan suhu manusia, pada respon antara low cutt off frekuensi (foL) dan high cut off frekuensi (foH). BPF ini dipilih sebagai media pemilah antara sinyal IR dari suhu tubuh manusia dengan sinyal suhu disekitarnya (noise), sinyal dari BPF ini akan dikomparasi menggunakan rangkaian komparator untuk menentukan level tegangan. Bila sinyal dari $\mathrm{BPF}$ ini melebihi dari level tegangan $+3,3 \mathrm{~V}$, maka dapat dikatakan bahwa sensor PIR350 ini telah berhasil memindai suhu manusia secara akurat.

Penguatan OpAmp dan frekeuensi cut off dari BPF dapat dihitung dengan persamaan matematis sederhana.

\section{HASIL DAN PEMBAHASAN}

Sinyal output dari pyroelectric dikuatkan dengan menggunakan 2 tingkat BPF Operational Amplifier (OpAmp) seperti yang ditunjukan pada gambar 6 [5].

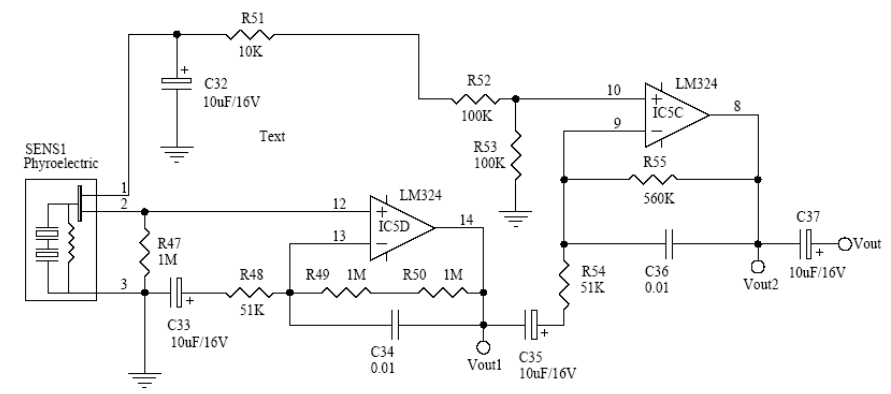

Gambar 6. Rangkaian penguat dua tingkat Phyroelectrik dengan BPF OpAmp

Penguat tingkat pertama IC5D, dibentuk dari non inverting OpAmp sehingga didapat persamaan matematis:

$$
\begin{aligned}
\mathrm{V}_{\text {Out } 1} & =\left(1+\left(\mathrm{R}_{49+} \mathrm{R}_{50}\right) / \mathrm{R}_{48}\right) \\
& =\left(1+2 \times 10^{6} / 51 \times 10^{3}\right)=40,2 \text { kali }
\end{aligned}
$$

Penguat tingkat kedua IC5C, dibentuk dari penguat inverting OpAmp sehingga sinyal keluaran akan terbalik $180^{\circ}$ dari sinyal masukannya, karena rangkaian menggunakan OpAmp dengan catu daya tunggal maka untuk menghindari output terpotong pada transisi negatif perlu tegangan bias sebesar $1 / 2$ VCC di pin non inverting OpAmp [6]. persamaan matematis penguatan inverting menjadi:

$$
\begin{aligned}
\mathrm{V}_{\text {Out } 2} & =\left(\left(\mathrm{P}_{3}+\mathrm{R}_{55}\right) / \mathrm{R}_{21}\right) \\
& =\left(2 \times 10^{6} / 51 \times 10^{3}\right)=39,2 \mathrm{kali}
\end{aligned}
$$

Sehingga total penguatan menjadi:

$$
\begin{aligned}
\mathrm{V}_{\text {Out }} & =\mathrm{V}_{\text {Out } 1} \times \mathrm{V}_{\text {Out2 }} \\
& =40,2 \times 39,2=1.576 \mathrm{kali}
\end{aligned}
$$

BPF dirancang hanya untuk mendeteksi pergerakan suhu manusia, pada respon antara low cutt off frekuensi (foL) dan high cut off frekuensi (foH) seperti yang terlihat pada gambar 7 .

Pada penguatan pertama dan penguatan kedua mempunyai konfigurasi BPF yang sama sehingga, 
setiap cut off frekuensi dapat dihitung dari penguatan pertama dengan persamaan matematis:

$$
\begin{aligned}
\text { foL } & =1 /\left(2 \pi \times \mathrm{C}_{33} \times\left(\mathrm{R}_{48}\right)\right) \\
& =1 /\left(2 \times 3,14 \times 10 \times 10^{-6} \times 51 \times 10^{3}\right) \\
& =1 /\left(6,28 \times 51 \times 10^{-2}\right)=0,31 \mathrm{~Hz} \\
\text { foH } & =1 /\left(2 \pi \times C_{34} \times\left(\mathrm{R}_{49}+\mathrm{R}_{50}\right)\right) \\
& =1 /\left(2 \times 3,14 \times 0,01 \times 10^{-6} \times 2 \times 10^{6}\right) \\
& =1 /\left(6,28 \times 2 \times 10^{-2}\right)=7,96 \mathrm{~Hz} .
\end{aligned}
$$

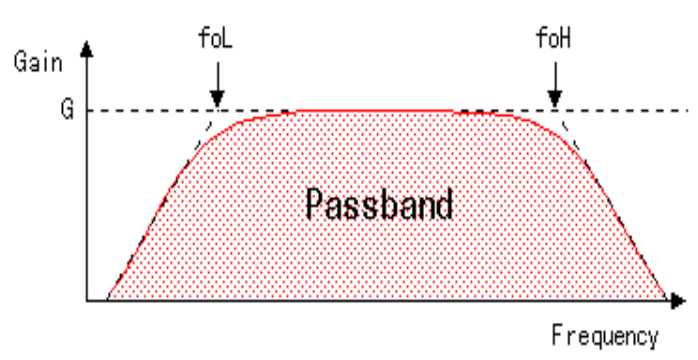

Gambar 7. Bandpass filter amplifier [6].

Setelah melalui penguatan dan filter, tegangan output akan masuk kedalam rangkaian komparator, rangkaian ini mendeteksi input tegangan di atas dan di bawah level tegangan yang telah di-set seperti yang terlihat pada gambar 8 berikut [6] .

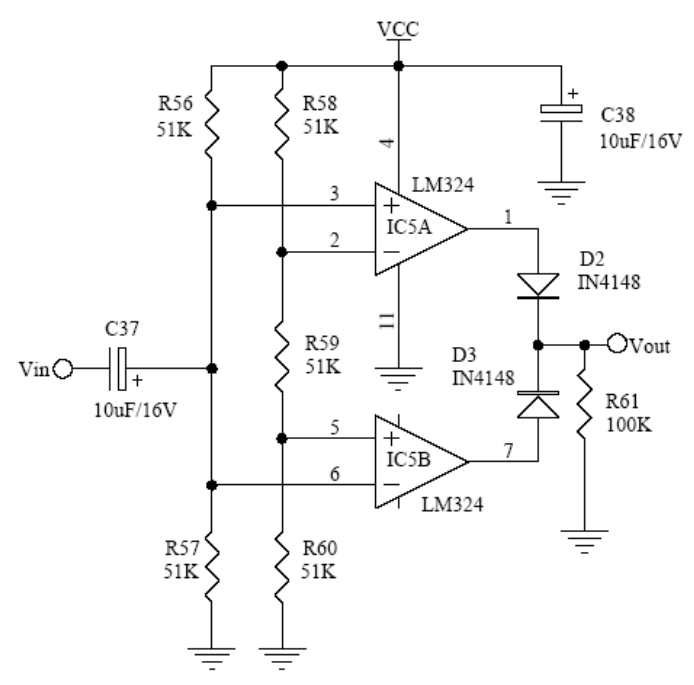

Gambar 8. Rangkaian komparator [6].

Pada OPAMP IC5A, tegangan $+3,3 \mathrm{~V}$ referensi diletakan pada input positif terminal sehingga kalau tegangan listrik dari input negatif terminal adalah kurang dari $+3,3 \mathrm{~V}$, maka keluaran adalah taraf tinggi (VCC) dan ketika tegangan listrik dari input negatif terminal menjadi lebih dari $+3,3 \mathrm{~V}$, keluaran menjadi taraf rendah (0 Volt).

Pada OpAmp IC5B, tegangan $+1,7 \mathrm{~V}$ referensi diletakan pada input negatif terminal sehingga kalau tegangan listrik dari input positif terminal lebih dari $+1,7 \mathrm{~V}$, maka keluaran adalah taraf tinggi (VCC) dan ketika ketika tegangan listrik dari input positif terminal menjadi kurang dari $+1,7 \mathrm{~V}$, keluaran menjadi taraf rendah (0 Volt). Bentuk sinyal masukan dan keluaran dari komparator ditunjukan dalam gambar 9 di bawah ini [6].

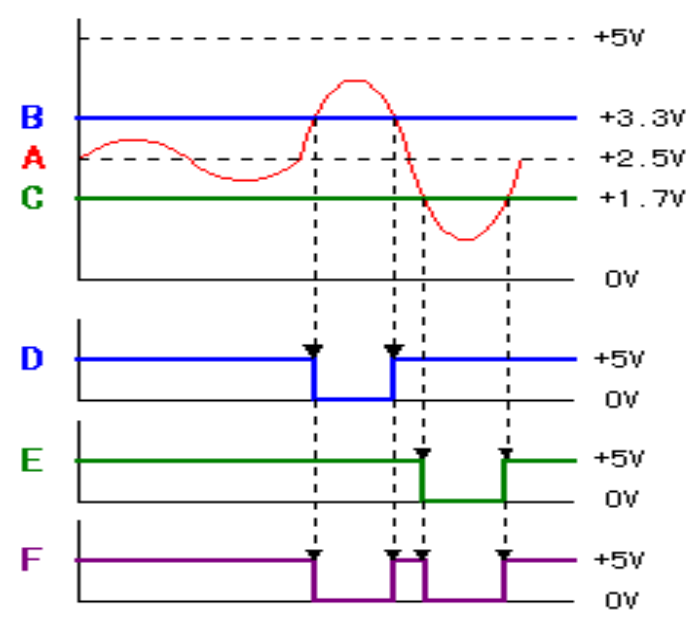

Gambar 9. Bentuk sinyal masukan dan keluaran rangkaian komparator [6].

Ilustrasi bagaimana sensor pyroelectrik mendeteksi sumber panas diperlihatkan pada gambar 10 di bawah ini [6].
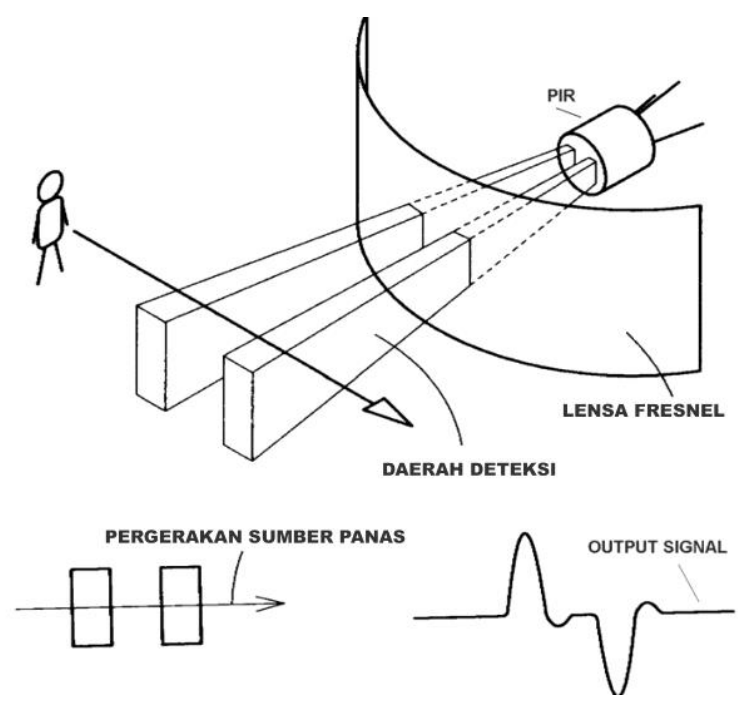

Gambar 10. Ilustrasi pemindaian sumber panas oleh sensor PIR325 


\section{KESIMPULAN}

Sinyal respon pemindaian suhu tubuh manusia sebagai akibat perubahan kapasitansi dalam amplifier dapat diamati dengan melihat waktu naik dan turun dari sinyal tegangan keluaran amplifier. Waktu naik dan turun dari signal tegangan didekatkan dengan meninjau representasi dari respon steady state, bila tanggapan ditunjukan oleh $\tau_{e}$ (tetapan waktu elektrik) dan $\tau_{t}$ (tetapan waktu termal), maka respon frekuensi Upper cutoff yang berhubungan dengan $\tau_{e}$ (tetapan waktu elektrik), dan lower cutoff frekuensi yang berhubungan dengan $\tau_{t}$ (tetapan waktu termal) dapat ditentukan.

Dengan penguatan 40,2 kali melalui rangkaian amplifier dan band pass filter, suhu tubuh manusia mampu dideteksi pada jarak 10 meter dengan sudut jelajah $120^{\circ}$.

Dari hasil pengamatan, inteferensi radiasi infra merah suhu di area pemindaian akan memberikan kontribusi dalam kesalahan pengukuran sehingga sensor perlu ditempatkan pada area yang lebih dingin.

\section{DAFTAR PUSTAKA}

[1] G Duke, Human-tracking systems using pyroelectric infrared, Paper 050734R, pp. 1-10, 2008, (diakses pada 17 April 2011).

[2] What is Infrared Radiation?, http://www.cctvinformation.co.uk/CCTV\%20Information.htm, (diakses pada 20 April 2011).

[3] Focusing devices for pyroelectric infrared sensors, http://www.glolab.com/focusdevices/focus.html, (diakses pada 22 Mei 2011).

[4] GLOLAB Corporation, PIR350 pyroelectric datasheet, http://www.glolab.com. 2000 (diakses pada 20 April 2011).

[5] How Infrared motion detector components work, www.glolab.com/pirparts/infrared.html, (diakses pada 10 Juni 2011).

[6] Circuit explanation for the infrared sensor, http:// www.interq.or.jp. (diakses pada 15 Juni 2011). 